\title{
A HISTÓRIA DA EDUCAÇÃO INFANTIL NO BRASIL: AVANÇOS, RETROCESSOS E DESAFIOS DESSA MODALIDADE EDUCACIONAL
}

\author{
Jaqueline Delgado Paschoal ${ }^{1}$ \\ Maria Cristina Gomes Machado ${ }^{2}$
}

UEM

\section{RESUMO:}

Este estudo tem como objetivo principal analisar, criticamente, a trajetória histórica das instituições de atendimento à criança, bem como discutir os avanços e retrocessos dessa modalidade educacional no Brasil. Entendemos que este trabalho, ao priorizar o movimento de investigar o passado, permite compreender os desafios que se coloca na sociedade contemporânea, sobretudo no que diz respeito à ação pedagógica dos professores que atuam junto a esse nível de ensino. Para o seu desenvolvimento, optamos pela pesquisa bibliográfica, tomando por base o Método Histórico, por considerar que, por meio dele, é possível conhecer a origem das primeiras instituições de atendimento à criança na Europa e suas diferentes funções no decorrer da história até sua propagação pelos outros continentes. É importante mencionar que as escolas infantis no Brasil sofreram, no decorrer dos tempos, diferentes mudanças em suas funções, as quais passaram pelo assistencialismo, custódia e privação cultural até a função educativa. Os resultados da pesquisa apontam que, do ponto de vista histórico, houve um avanço significativo da legislação quando esta reconheceu a criança como cidadã, como sujeito de direitos, inclusive o direito à educação de qualidade desde o nascimento.

Palavras-chave: História da Educação. Fontes e Fundamentos. Educação Pública. Educação Infantil.

\section{HISTORY OF CHILDREN EDUCATION IN BRAZIL: ADVANCES, BACKSPACE AND EDUCATIONAL CHALLENGES THAT TYPE}

\begin{abstract}
:
This study has as main objective, to critically analyze the historical trajectory of institutions for care of children and discuss the advances and setbacks of this type of education in Brazil. We justify the intention of the work, therefore, the movement to investigate the past, incorporating the marks of the creation and consolidation of these institutions, can understand the challenges that arise in contemporary society, especially as regards the pedagogical action of the teachers who work with that kind of teaching. For the development of the article, we opted for the literature search, based on the Historical method, considering that, through that, it is possible to know the origin of the first institutions for care of children in Europe and its different functions in the course of history by its spread on other continents. It is important to mention that the children schools in Brazil have suffered in the course of time, different changes in their functions, through the care, custody and cultural deprivation to the educational function. The survey results indicate that from a historical perspective, there was a significant advance of the legislation when it recognizes the child as citizen, as a subject of rights, including the right to quality education from birth.
\end{abstract}

Keywords: History of Education; Sources and Grounds, Public Education, Children Education. 


\section{Introdução}

Falar da creche ou da educação infantil é muito mais do que falar de uma instituição, de suas qualidades e defeitos, da sua necessidade social ou da sua importância educacional. É falar da criança. De um ser humano, pequenino, mas exuberante de vida. (DIDONET, 2001).

Do ponto de vista histórico, a educação da criança esteve sob a responsabilidade exclusiva da família durante séculos, porque era no convívio com os adultos e outras crianças que ela participava das tradições e aprendia as normas e regras da sua cultura. $\mathrm{Na}$ sociedade contemporânea, por sua vez, a criança tem a oportunidade de frequentar um ambiente de socialização, convivendo e aprendendo sobre sua cultura mediante diferentes interações com seus pares. Dessa maneira, o presente artigo tem como objetivo traçar a trajetória histórica da educação infantil no Brasil, analisando, criticamente, os avanços e retrocessos dessa modalidade educacional e sinalizando para os desafios que se colocam na busca pela qualidade na organização do trabalho pedagógico dessas instituições.

Este estudo justifica-se porque, apesar dos inúmeros avanços tecnológicos, bem como a contribuição das ciências ao longo dos anos e o avanço significativo da legislação brasileira no que diz respeito ao direito da criança à educação de qualidade desde o nascimento, a realidade denuncia um grande descompasso entre o discurso da lei e o cotidiano de muitas escolas infantis.

Para investigar esse descompasso, optamos pela pesquisa bibliográfica, tomando por base o Método Histórico, já que a discussão sobre os avanços e retrocessos desse nível de ensino no Brasil, pressupõe conhecer, num primeiro momento, as marcas do processo de criação e expansão dessas instituições na Europa e Estados Unidos, procurando mostrar que tanto as creches como as escolas maternais tiveram uma preocupação com as questões pedagógicas e não somente com os cuidados da criança. Este posicionamento derruba o discurso de que, na sua origem, essas instituições tiveram apenas uma função assistencialista, diferenciando-se de outros estabelecimentos, como, por exemplo, os jardins de infância, que, já na sua criação, apresentavam um trabalho voltado não só para os cuidados infantis, mas para um trabalho eminentemente pedagógico.

Do desenvolvimento desta questão, originou-se o presente artigo, dividido em três partes. Na primeira, apresentamos a configuração da preocupação com a educação das crianças em instituições regulamentadas. $\mathrm{Na}$ segunda parte, analisamos seu processo histórico no Brasil, enfatizando sua origem e consolidação. Na última parte, destacamos a criação da legislação para regulamentar e garantir a oferta da educação infantil às crianças de diferentes classes sociais.

\section{A educação da criança no movimento universal}

Na Europa, com a transição do feudalismo para o capitalismo, em que houve a passagem do modo de produção doméstico para o sistema fabril, e, consequentemente, a substituição das ferramentas pelas máquinas e a substituição da força humana pela força motriz, provocando toda uma reorganização da sociedade. $\mathrm{O}$ enorme impacto causado pela revolução industrial fez com que toda a classe operária se submetesse ao regime da fábrica e das máquinas. Desse modo, essa revolução possibilitou a entrada em massa da mulher no mercado de trabalho, alterando a forma da família cuidar e educar seus filhos. 
Marx (1986), ao discutir a apropriação pelo capital das forças de trabalho suplementares, enfatiza que a maquinaria permitiu o emprego de trabalhadores sem força muscular e com membros mais flexíveis, o que possibilitou ao capital absorver as mulheres e as crianças nas fábricas. A maquinaria estabeleceu um meio de diversificar os assalariados, colocando, nas fábricas, todos os membros da família do trabalhador, independentemente do sexo e da idade de cada um. Se, até então, o trabalhador vendia somente sua própria força de trabalho, passou a vender a força da mulher e dos filhos.

$\mathrm{Na}$ realidade, apesar do aumento significativo do número de trabalhadores, os homens foram, em parte, substituídos no trabalho pelas mulheres e pelas crianças, já que a lei fabril exigia duas turmas trabalhando: uma turma de seis horas e outra de quatro, ou cada uma, cinco horas apenas. Mas os pais não queriam vender o tempo parcial das crianças mais barato do que vendiam antes o tempo integral, mesmo que as condições de trabalho fossem péssimas. A passagem seguinte evidencia a precariedade do trabalho e a necessidade de sucumbir aos ditames do capital: “[...] o capital achava nelas, as mulheres e moças despidas, muitas vezes em conjunto com homens, perfeitamente de acordo com seu código moral" (MARX, 1986, p. 451).

O nascimento da indústria moderna alterou profundamente a estrutura social vigente, modificando os hábitos e costumes das famílias. As mães operárias que não tinham com quem deixar seus filhos, utilizavam o trabalho das conhecidas mães mercenárias. Essas, ao optarem pelo não trabalho nas fábricas, vendiam seus serviços para abrigarem e cuidarem dos filhos de outras mulheres.

Em função da crescente participação dos pais no trabalho das fábricas, fundições e minas de carvão, surgiram outras formas de arranjos mais formais de serviços de atendimento das crianças. Eram organizados por mulheres da comunidade que, na realidade, não tinham uma proposta instrucional formal, mas adotavam atividades de canto e de memorização de rezas (RIZZO, 2003). As atividades relacionadas ao desenvolvimento de bons hábitos de comportamento e de internalização de regras morais eram reforçadas nos trabalhos dessas voluntárias.

Criou-se uma nova oferta de emprego para as mulheres, mas aumentaram os riscos de maus tratos às crianças, reunidas em maior número, aos cuidados de uma única, pobre e despreparada mulher. Tudo isso, aliado a pouca comida e higiene, gerou um quadro caótico de confusão, que terminou no aumento de castigos e muita pancadaria, a fim de tornar as crianças mais sossegadas e passivas. Mais violência e mortalidade infantil. (RIZZO, 2003, p. 31).

A preocupação das famílias pobres era sobreviver, segundo essa autora, sendo assim, os maus tratos e o desprezo pelas crianças tornaram-se aceitos como regra e costume pela sociedade de um modo geral. As mazelas contra a infância se tornaram tão comuns que, por filantropia, algumas pessoas resolveram tomar para si a tarefa de acolher as crianças desvalidas que se encontravam nas ruas. A sociedade aplaudiu, uma vez que todos queriam ver as ruas limpas do estorvo e da sujeira provocados pelas crianças abandonadas.

As primeiras instituições na Europa e Estados Unidos tinham como objetivos cuidar e proteger as crianças enquanto às mães saíam para o trabalho. Desta maneira, sua origem e expansão como instituição de cuidados à criança estão associadas à transformação da família, de extensa para nuclear. Sua origem, na sociedade ocidental, de acordo com Didonet (2001), baseia-se no trinômio: mulher-trabalho-criança. As creches, escolas 
maternais e jardins de infância tiveram, somente no seu início, o objetivo assistencialista, cujo enfoque era a guarda, higiene, alimentação e os cuidados físicos das crianças.

Apesar de seu início estar mais voltado para as questões assistenciais e de custódia, Kuhlmann (2001) ressalta que essas instituições se preocuparam com questões não só de cuidados, mas de educação, visto se apresentarem como pedagógicas já em seu início. Exemplifica sua defesa com a "Escola de Principiantes" ou escola de tricotar, criada pelo pastor Oberlin, na França em meados de 1769, para crianças de dois a seis anos de idade. Esse pastor criou apenas um programa de passeios, trabalhos manuais e histórias contadas com gravuras, nos quais suas escolas de tricô tinham como objetivo, por meio do trabalho de mulheres da comunidade, tomar conta de crianças, ensinando-lhes a ler a bíblia e a tricotar. De acordo com seus objetivos, nesses espaços, as crianças deveriam aprender diferentes habilidades, como adquirir hábitos de obediência, bondade, identificar as letras do alfabeto, pronunciar bem as palavras e assimilar noções de moral e religião.

A escola de Robert Owen, criada no ano de 1816 em New Lanark, na Escócia, também é um exemplo de que essas instituições foram pensadas na perspectiva pedagógica, já que sua escola recebia crianças de dezoito meses até vinte cinco anos de idade e tinha como objetivo trabalhar lições que abordavam a natureza, exercícios de dança e de canto coral. Os materiais didáticos tinham um propósito educativo, porque possibilitavam às crianças o desenvolvimento do raciocínio e o julgamento correto diante das situações propostas pelo professor.

A sala de asilo francesa, desde os primeiros textos oficiais, foi concebida sob uma perspectiva de prover cuidados e educação moral e intelectual às crianças. "[...] o seu papel não foi somente o de guardar a pequena infância popular, mas, em nome de um projeto educativo, de disputar esta clientela às guardiãs de quarteirão" (KUHLMANN, 2001, p. 8). A intenção dessas instituições era, primeiramente, retirar das ruas as crianças em situação de risco e dos perigos a que estavam expostas; em seguida, proporcionar-lhes o desenvolvimento da inteligência e dos bons costumes, segundo o autor citado.

Do ponto de vista histórico, a própria literatura traz o jardim de infância como uma instituição exclusivamente pedagógica e que, desde sua origem, teve pouca preocupação com os cuidados físicos das crianças. No entanto, vale ressaltar que o primeiro Jardim de Infância, criado, em meados de 1840 em Blankenburgo, por Froebel, tinha uma preocupação não só de educar e cuidar das crianças, mas de transformar a estrutura familiar de modo que as famílias pudessem cuidar melhor de seus filhos.

Os estudos que atribuem aos Jardins de Infância uma dimensão educacional e não assistencial, como outras instituições de educação infantil, deixam de levar em conta as evidências históricas que mostram uma estreita relação entre ambos os aspectos: a que a assistência é que passou, no final do século XIX, a privilegiar políticas de atendimento à infância em instituições educacionais e o Jardim de Infância foi uma delas, assim como as creches e escolas maternais. (KUHLMANN, 2001, p. 26).

A partir da segunda metade do século XIX, o quadro das instituições destinadas à primeira infância era formado basicamente da creche e do jardim de infância ao lado de outras modalidades educacionais, que foram absorvidas como modelos em diferentes países. No Brasil, por exemplo, a creche foi criada exclusivamente com caráter assistencialista, o que diferenciou essa instituição das demais criadas nos países europeus e norte-americanos, que tinham nos seus objetivos o caráter pedagógico. Essas diferenças exigem que seja analisada na sua especificidade, para que se possa compreender a 
trajetória desse nível de ensino no caso brasileiro e na relação que estabelece com o contexto universal.

\section{A educação das crianças: a particularidade brasileira}

Diferentemente dos países europeus, no Brasil, as primeiras tentativas de organização de creches, asilos e orfanatos surgiram com um caráter assistencialista, com o intuito de auxiliar as mulheres que trabalhavam fora de casa e as viúvas desamparadas. Outro elemento que contribuiu para o surgimento dessas instituições foram as iniciativas de acolhimento aos órfãos abandonados que, apesar do apoio da alta sociedade, tinham como finalidade esconder a vergonha da mãe solteira, já que as crianças "[...] eram sempre filhos de mulheres da corte, pois somente essas tinham do que se envergonhar e motivo para se descartar do filho indesejado" (RIZZO, 2003, p. 37). Numa sociedade patriarcal, a idéia era criar uma solução para os problemas dos homens, ou seja, retirar dos mesmos a responsabilidade de assumir a paternidade. Considerando que, nessa época, não se tinha um conceito bem definido sobre as especificidades da criança, a mesma era "[...] concebida como um objeto descartável, sem valor intrínseco de ser humano" (RIZZO, 2003, p. 37).

Fatores como o alto índice de mortalidade infantil, a desnutrição generalizada e o número significativo de acidentes domésticos, fizeram com que alguns setores da sociedade, dentre eles os religiosos, os empresários e educadores, começassem a pensar num espaço de cuidados da criança fora do âmbito familiar. De maneira que foi com essa preocupação, ou com esse "[...] problema, que a criança começou a ser vista pela sociedade e com um sentimento filantrópico, caritativo, assistencial é que começou a ser atendida fora da família" (DIDONET, 2001, p. 13).

Enquanto para as famílias mais abastadas pagavam uma babá, as pobres se viam na contingência de deixar os filhos sozinhos ou colocá-los numa instituição que deles cuidasse. Para os filhos das mulheres trabalhadoras, a creche tinha que ser de tempo integral; para os filhos de operárias de baixa renda, tinha que ser gratuita ou cobrar muito pouco; ou para cuidar da criança enquanto a mãe estava trabalhando fora de casa, tinha que zelar pela saúde, ensinar hábitos de higiene e alimentar a criança. A educação permanecia assunto de família. Essa origem determinou a associação creche, criança pobre e o caráter assistencial da creche. (DIDONET, 2001, p. 13).

É interessante ressaltar que, ao longo das décadas, arranjos alternativos foram se constituindo no sentido de atender às crianças das classes menos favorecidas. Uma das instituições brasileiras mais duradouras de atendimento à infância, que teve seu início antes da criação das creches, foi a roda dos expostos ou roda dos excluídos. Esse nome provém do dispositivo onde se colocavam os bebês abandonados e era composto por uma forma cilíndrica, dividida ao meio por uma divisória e fixado na janela da instituição ou das casas de misericórdia. Assim, a criança era colocada no tabuleiro pela mãe ou qualquer outra pessoa da família; essa, ao girar a roda, puxava uma corda para avisar a rodeira que um bebê acabava de ser abandonado, retirando-se do local e preservando sua identidade.

Por mais de um século a roda de expostos foi à única instituição de assistência à criança abandonada no Brasil e, apesar dos movimentos contrários a essa instituição por parte de um segmento da sociedade, foi somente no século XX, já em meados de 1950, que 
o Brasil efetivamente extinguiu-a, sendo o último país a acabar com o sistema da roda dos enjeitados (MARCÍLIO, 1997).

Ainda no final do século XIX, período da abolição da escravatura no país, quando se acentuou a migração para as grandes cidades e o início da República, houve iniciativas isoladas de proteção à infância, no sentido de combater os altos índices de mortalidade infantil. Mesmo com o trabalho desenvolvido nas casas de Misericórdia, por meio da roda dos expostos, um número significativo de creches foi criado não pelo poder público, mas exclusivamente por organizações filantrópicas. Se, por um lado, os programas de baixo custo, voltados para o atendimento às crianças pobres, surgiam no sentido de atender às mães trabalhadoras que não tinham onde deixar seus filhos, a criação dos jardins de infância foi defendida, por alguns setores da sociedade, por acreditarem que os mesmos trariam vantagens para o desenvolvimento infantil, ao mesmo tempo foi criticado por identificá-los com instituições européias.

As tendências que acompanharam a implantação de creches e jardins de infância, no final do século XIX e durante as primeiras décadas do século XX no Brasil, foram: a jurídico-policial, que defendia a infância moralmente abandonada, a médico-higienista e a religiosa, ambas tinham a intenção de combater o alto índice de mortalidade infantil tanto no interior da família como nas instituições de atendimento à infância. Na realidade, cada instituição "[...] apresentava as suas justificativas para a implantação de creches, asilos e jardins de infância onde seus agentes promoveram a constituição de associações assistenciais privadas" (KUHLMANN Jr., 1998, p. 88).

Nesse período, foi criado o Instituto de Proteção à Infância do Rio de Janeiro pelo médico Arthur Moncorvo Filho, que tinha como objetivos não só atender às mães grávidas pobres, mas dar assistência aos recém-nascidos, distribuição de leite, consulta de lactantes, vacinação e higiene dos bebês. Foi considerada umas das entidades mais importantes, mormente por ter expandido seus serviços por todo o território brasileiro. Outra instituição importante criada nesse ano foi o Instituto de Proteção e Assistência à Infância, este precedeu, em 1919, a criação do Departamento da Criança, que tinha como objetivo não só fiscalizar as instituições de atendimento à criança, mas combater o trabalho das mães voluntárias que cuidavam, de maneira precária, dos filhos das trabalhadoras (KUHLMANN Jr., 1998).

Devido a muitos fatores, como o processo de implantação da industrialização no país, a inserção da mão-de-obra feminina no mercado de trabalho e a chegada dos imigrantes europeus no Brasil, os movimentos operários ganharam força. Eles começaram a se organizar nos centros urbanos mais industrializados e reivindicavam melhores condições de trabalho; dentre estas, a criação de instituições de educação e cuidados para seus filhos.

Os donos das fábricas, por seu lado, procurando diminuir a força dos movimentos operários, foram concedendo certos benefícios sociais e propondo novas formas de disciplinar seus trabalhadores. Eles buscavam o controle do comportamento dos operários, dentro e fora da fábrica. Para tanto, vão sendo criadas vilas operárias, clubes esportivos e também creches e escolas maternais para os filhos dos operários. O fato dos filhos das operárias estarem sendo atendidos em creches, escolas maternais e jardins de infância, montadas pelas fábricas, passou a ser reconhecido por alguns empresários como vantajoso, pois mais satisfeitas, as mães operárias produziam melhor. (OLIVEIRA, 1992, p. 18). 
Ao longo das décadas, as poucas conquistas não se fizeram sem conflitos. Com o avanço da industrialização e o aumento das mulheres da classe média no mercado de trabalho, aumentou a demanda pelo serviço das instituições de atendimento à infância. Para Haddad (1993), os movimentos feministas que partiram dos Estados Unidos tiveram papel especial na revisão do significado das instituições de atendimento à criança, porque as feministas mudaram seu enfoque, defendendo a idéia de que tanto as creches como as préescolas3 deveriam atender a todas as mulheres, independentemente de sua necessidade de trabalho ou condição econômica. O resultado desse movimento culminou no aumento do número de instituições mantidas e geridas pelo poder público.

Essas instituições ganharam enfoque diferente, passando a ser reivindicadas como um direito de todas as mulheres trabalhadoras e era baseado no movimento da teoria da privação cultural. Essa teoria, defendida tanto nos Estados Unidos na década de sessenta como no Brasil já em meados de 1970, considerava que o atendimento à criança pequena fora do lar possibilitaria a superação das precárias condições sociais a que ela estava sujeita. Era a defesa de uma educação compensatória.

Kramer (1995, p. 24), ao discutir esse assunto, ressalta que o discurso do poder público, em defesa do atendimento das crianças das classes menos favorecidas, parte de determinada concepção de infância, já que o mesmo reconhece esse período da vida da criança de maneira padronizada e homogênea. A idéia é a de que as crianças oriundas das classes sociais dominadas são consideradas "[...] carentes, deficientes e inferiores na medida em que não correspondem ao padrão estabelecido; faltariam a essas crianças privadas culturalmente, determinados atributos ou conteúdos que deveriam ser nelas incutidos". Por esse motivo e a fim de superar as deficiências de saúde e nutrição, assim como as deficiências escolares, são oferecidas diferentes propostas no sentido de compensar tais carências. Nessa perspectiva, a pré-escola funcionaria, segundo a autora, como mola propulsora da mudança social, uma vez que possibilitaria a democratização das oportunidades educacionais.

Ambas as funções podem ser desmistificadas. Ao nível da primeira função, considera-se a educação como promotora da melhoria social, o que é uma maneira de esconder os reais problemas da sociedade e de evitar a discussão dos aspectos políticos e econômicos mais complexos. A proposta que ressurge, de elaborar programas de educação pré-escolar a fim de transformar a sociedade no futuro, é uma forma de culpar o passado pela situação de hoje e de focalizar no futuro quaisquer possibilidades de mudança. Fica-se, assim, isento de realizar no presente ações ou transformações significativas que visem a atender às necessidades sociais atuais (KRAMER, 1995, p. 30).

Enquanto as instituições públicas atendiam às crianças das camadas mais populares, as propostas das particulares, de cunho pedagógico, funcionavam em meio turno, dando ênfase à socialização e à preparação para o ensino regular. Nota-se que as crianças das diferentes classes sociais eram submetidas a contextos de desenvolvimento diferentes, já que, enquanto as crianças das classes menos favorecidas eram atendidas com propostas de trabalho que partiam de uma idéia de carência e deficiência, as crianças das classes sociais mais abastadas recebiam uma educação que privilegiava a criatividade e a sociabilidade infantil (KRAMER, 1995).

Com a preocupação de atendimento a todas as crianças, independente da sua classe social, iniciou-se um processo de regulamentação desse trabalho no âmbito da legislação. 


\section{A educação infantil e a legislação brasileira}

Verifica-se que, até meados do final dos anos setenta, pouco se fez em termos de legislação que garantisse a oferta desse nível de ensino. Já na década de oitenta, diferentes setores da sociedade, como organizações não-governamentais, pesquisadores na área da infância, comunidade acadêmica, população civil e outros, uniram forças com o objetivo de sensibilizar a sociedade sobre o direito da criança a uma educação de qualidade desde o nascimento. Do ponto de vista histórico, foi preciso quase um século para que a criança tivesse garantido seu direito à educação na legislação, foi somente com a Carta Constitucional de 1988 que esse direito foi efetivamente reconhecido.

De acordo com Bittar (2003, p. 30), o esforço coletivo dos diversos segmentos visava assegurar na Constituição, "[...] os princípios e as obrigações do Estado com as crianças". Assim, foi possível sensibilizar a maioria dos parlamentares e assegurar na Constituição brasileira o direito da criança à educação. A pressão desses movimentos na Assembléia Constituinte possibilitou a inclusão da creche e da pré-escola no sistema educativo ao inserir, na Constituição Federal de 1988, em seu em seu artigo 208, o inciso IV: “[...] O dever do Estado para com a educação será efetivado mediante a garantia de oferta de creches e pré-escolas às crianças de zero a seis anos de idade" (BRASIL, 1988). A partir dessa Lei, as creches, anteriormente vinculadas à área de assistência social, passaram a ser de responsabilidade da educação. Tomou-se por orientação o princípio de que essas instituições não apenas cuidam das crianças, mas devem, prioritariamente, desenvolver um trabalho educacional.

A Constituição representa uma valiosa contribuição na garantia de nossos direitos, visto que, por ser fruto de um grande movimento de discussão e participação da população civil e poder público, "[...] foi um marco decisivo na afirmação dos direitos da criança no Brasil" (LEITE FILHO, 2001, p. 31). Na realidade, foi somente com a Constituição que a criança de zero a seis anos ${ }^{4}$ foi concebida como sujeito de direitos.

Dois anos após a aprovação da Constituição Federal de 1988, foi aprovado o Estatuto da Criança e do Adolescente ${ }^{5}$ - Lei 8.069/90, que, ao regulamentar o art. 227 da Constituição Federal, inseriu as crianças no mundo dos direitos humanos. De acordo com seu artigo $3^{\circ}$, a criança e o adolescente devem ter assegurados os direitos fundamentais inerentes à pessoa humana, para que seja possível, desse modo, ter acesso às oportunidades de "[...] desenvolvimento físico, mental, moral, espiritual e social, em condições de liberdade e dignidade" (BRASIL, 1994a).

Segundo Ferreira (2000, p. 184), essa Lei é mais do que um simples instrumento jurídico, porque:

Inseriu as crianças e adolescentes no mundo dos direitos humanos. O ECA estabeleceu um sistema de elaboração e fiscalização de políticas públicas voltadas para a infância, tentando com isso impedir desmandos, desvios de verbas e violações dos direitos das crianças. Serviu ainda como base para a construção de uma nova forma de olhar a criança: uma criança com direito de ser criança. Direito ao afeto, direito de brincar, direito de querer, direito de não querer, direito de conhecer, direito de sonhar. Isso quer dizer que são atores do próprio desenvolvimento.

Nos anos seguintes à aprovação do Estatuto da Criança e do Adolescente, entre os anos de 1994 a 1996, foi publicado pelo Ministério da Educação uma série de documentos importantes intitulados: "Política Nacional de Educação Infantil". Tais documentos 
estabeleceram as diretrizes pedagógicas e de recursos humanos com o objetivo de expandir a oferta de vagas e promover a melhoria da qualidade de atendimento nesse nível de ensino: "Critérios para um atendimento em creches que respeite os direitos fundamentais das crianças", que discute a organização e o funcionamento interno dessas instituições; "Por uma política de formação do profissional de educação infantil", que reafirma a necessidade e a importância de um profissional qualificado e um nível mínimo de escolaridade para atuar nas instituições de educação infantil; "Educação infantil: bibliografia anotada" e "Propostas pedagógicas e currículo em educação infantil". Esses documentos foram importantes no sentido de garantir melhores possibilidades de organização do trabalho dos professores no interior dessas instituições.

Além da Constituição Federal de 1988, do Estatuto da Criança e do Adolescente de 1990, destaca-se a Lei de Diretrizes e Bases da Educação Nacional de 1996, que, ao tratar da composição dos níveis escolares, inseriu a educação infantil como primeira etapa da Educação Básica. Essa Lei define que a finalidade da educação infantil é promover o desenvolvimento integral da criança até seis anos de idade, complementando a ação da família e da comunidade (BRASIL, 1996). De acordo com o Ministério da Educação, o tratamento dos vários aspectos como dimensões do desenvolvimento e não áreas separadas foi fundamental, já que "[...] evidencia a necessidade de se considerar a criança como um todo, para promover seu desenvolvimento integral e sua inserção na esfera pública" (BRASIL, 2006, p. 10).

Desse modo, verifica-se um grande avanço no que diz respeito aos direitos da criança pequena, uma vez que a educação infantil, além de ser considerada a primeira etapa da Educação Básica, embora não obrigatória, é um direito da criança e tem o objetivo de proporcionar condições adequadas para o desenvolvimento do bem-estar infantil, como o desenvolvimento físico, motor, emocional, social, intelectual e a ampliação de suas experiências. Diante dessa nova perspectiva, três importantes objetivos, devem, necessariamente, coroar essa nova modalidade educacional:

- Objetivo Social: associado à questão da mulher enquanto participante da vida social, econômica, cultural e política;

- Objetivo Educativo: organizado para promover a construção de novos conhecimentos e habilidades da criança;

- Objetivo Político: associado à formação da cidadania infantil, em que, por meio deste, a criança tem o direito de falar e de ouvir, de colaborar e de respeitar e ser respeitada pelos outros (DIDONET, 2001).

Em consonância com a legislação, o Ministério da Educação publicou, em 1998, dois anos após a aprovação da LDB, os documentos "Subsídios para o credenciamento e o funcionamento das instituições de educação infantil" (BRASIL, 1998b), que contribuiu significativamente para a formulação de diretrizes e normas da educação da criança pequena em todo o país, e o "Referencial Curricular Nacional para a Educação Infantil" (BRASIL, 1998a), com o objetivo de contribuir para a implementação de práticas educativas de qualidade no interior dos Centros de Educação Infantil. Este último foi concebido de maneira a servir como um guia de reflexão de cunho educacional sobre os objetivos, conteúdos e orientações didáticas para os profissionais que atuam com crianças de zero a seis anos de idade. Sobre os objetivos gerais da educação infantil, esse documento ressalta que a prática desenvolvida nessas instituições deve se organizar de modo que as crianças desenvolvam as seguintes capacidades: 
- $\quad$ desenvolver uma imagem positiva de si, atuando de forma cada vez mais independente, com confiança em suas capacidades e percepção de suas limitações;

- descobrir e conhecer progressivamente seu próprio corpo, suas potencialidades e seus limites, desenvolvendo e valorizando hábitos de cuidado com a própria saúde e bem-estar;

- estabelecer vínculos afetivos e de troca com adultos e crianças, fortalecendo sua auto-estima e ampliando gradativamente suas possibilidades de comunicação e interação social;

- $\quad$ estabelecer e ampliar cada vez mais as relações sociais, aprendendo aos poucos a articular seus interesses e pontos de vista com os demais, respeitando a diversidade e desenvolvendo atitudes de ajuda e colaboração;

- observar e explorar o ambiente com atitude de curiosidade, percebendo-se cada vez mais como integrante, dependente e agente transformador do meio ambiente e valorizando atitudes que contribuam para sua conservação;

- brincar, expressando emoções, sentimentos, pensamentos, desejos e necessidades;

- utilizar as diferentes linguagens (corporal, musical, plástica, oral e escrita) ajustadas às diferentes intenções e situações de comunicação, de forma a compreender e ser compreendido, expressar suas idéias, sentimentos, necessidades e desejos e avançar no seu processo de construção de significados, enriquecendo cada vez mais sua capacidade expressiva;

- $\quad$ conhecer algumas manifestações culturais, demonstrando atitudes de interesse, respeito e participação frente a elas e valorizando a diversidade (BRASIL, 1998a, p. 63, v. 1).

Para que esses objetivos sejam alcançados de modo integrado, o Referencial Curricular Nacional para a Educação Infantil (1998a) sugere que as atividades devem ser oferecidas para as crianças não só por meio das brincadeiras, mas aquelas advindas de situações pedagógicas orientadas. Nesse sentido, a integração entre ambos os aspectos é relevante no desenvolvimento do trabalho do professor, uma vez que:

Educar significa, portanto, propiciar situações de cuidados, brincadeiras e aprendizagens orientadas de forma integrada e que possam contribuir para o desenvolvimento das capacidades infantis de relação interpessoal, de ser e estar com os outros, em uma atitude de aceitação, respeito e confiança, e o acesso pelas crianças, aos conhecimentos mais amplos da realidade social e cultural (BRASIL, 1998a, p. 23).

Sobre o cuidar, é importante ressaltar que esse deve ser entendido como parte integrante da educação, ou seja: "[...] cuidar de uma criança em um contexto educativo demanda a integração de vários campos de conhecimentos e a cooperação de profissionais de diferentes áreas" (BRASIL, 1998a, p. 24). Ainda nos anos de 1998 e 1999, o Conselho Nacional de Educação, aprovou as Diretrizes Curriculares Nacionais para a Educação Infantil (BRASIL, 1998), que teve como objetivo direcionar, de modo obrigatório, os encaminhamentos de ordem pedagógica para esse nível de ensino aos sistemas municipais e estaduais de educação e as Diretrizes Curriculares para a Formação de Professores da 
Educação Infantil e Anos Iniciais do Ensino Fundamental, que também contribuiu para a melhoria de ambos os níveis de ensino ao discutir a relevância de uma formação altamente qualificada para esses profissionais.

Barreto (1998) ressalta que, apesar do avanço da legislação no que diz respeito ao reconhecimento da criança à educação nos seus primeiros anos de vida, também é importante considerar os inúmeros desafios impostos para o efetivo atendimento desse direito, que podem ser resumidos em duas grandes questões: a de acesso e a da qualidade do atendimento. Quanto ao acesso, a autora enfatiza que, mesmo tendo havido, nas últimas décadas, uma significativa expansão do atendimento, a entrada da criança na creche ainda deixa a desejar, em especial porque as crianças de famílias de baixa renda estão tendo menores oportunidades que as de nível socioeconômico mais elevado. Sobre a qualidade do atendimento, ressalta:

As instituições de educação infantil no Brasil, devido à forma como se expandiu, sem os investimentos técnicos e financeiros necessários, apresenta, ainda, padrões bastante aquém dos desejados [...] a insuficiência e inadequação de espaços físicos, equipamentos e materiais pedagógicos; a não incorporação da dimensão educativa nos objetivos da creche; a separação entre as funções de cuidar e educar, a inexistência de currículos ou propostas pedagógicas são alguns problemas a enfrentar. (BARRETO, 1998, p. 25).

A busca da qualidade envolve outras questões complexas, segundo essa autora, como o projeto educativo das instituições, formação e valorização do professor e recursos financeiros destinados a essa faixa etária, sendo necessário, contudo, garantir que esses recursos sejam efetivamente empregados nesse nível de ensino. Para que essa finalidade seja cumprida no âmbito da legislação, foi aprovada, no ano de 2001, a Lei no ${ }^{\circ} 10.172 / 2001$ - Plano Nacional de Educação, que teve por objetivo principal estabelecer as metas para todos os níveis de ensino, cuja vigência se estenderá até o ano de 2010.

Um dos objetivos desse documento é reduzir as desigualdades sociais e regionais no que diz respeito à entrada e à permanência da criança e do adolescente no ensino público, princípio que se aplica à educação infantil, visto ser a desigualdade de acesso bastante significativa nas classes menos favorecidas (BARRETO, 2003). Esse documento estabeleceu originalmente, para a educação infantil, vinte e seis metas para serem alcançadas no decorrer dos seus dez anos de vigência. Como não é objetivo deste trabalho analisar todas as vinte e seis metas do PNE, serão priorizadas duas questões fundamentais para a concretização de todas as demais metas: a oferta e o atendimento à educação infantil.

Sobre isso, Brandão (2007) ressalta que as metas $n^{\circ} 1,18,22$ e 23 do Plano Nacional de Educação (PNE) trataram especificamente sobre essas questões. A primeira meta trata da ampliação da oferta de atendimento às crianças de zero a seis de idade, dificilmente esta será alcançada, haja vista que a elevação do número de vagas exige um investimento financeiro bastante elevado para esse nível de ensino.

[...] tais investimentos teriam que ser feitos nos próximos seis anos, o que, dada a ênfase da política macroeconômica atual, focalizada na realização de um elevado superávit primário para pagamento de juros, encargos e serviços da dívida externa brasileira, torna-se difícil acreditar que os mesmos serão efetivados (BRANDÃO, 2007, p. 81). 
Como uma das prioridades do PNE (BRASIL, 2001) é a extensão da escolaridade obrigatória para crianças de seis anos de idade, incluindo-as nos anos iniciais do ensino fundamental, provavelmente, diminuirá o número de crianças frequentando a educação infantil; fator que poderá minimizar o impacto de demanda desse nível de ensino. A segunda meta, $\mathrm{n}^{\circ} 18$, que propõe a oferta e o atendimento com qualidade, Brandão (2007) esclarece que, embora não haja dúvida de que o cumprimento só trará benefícios às crianças, o problema é que a meta que prevê a adoção progressiva do atendimento em tempo integral inviabiliza tal atendimento, uma vez que "[...] corre-se o risco de nunca virmos a ter tal atendimento, visto que ainda não conseguimos, sequer, adotá-lo para as crianças do Ensino Fundamental" (BRANDÃO, 2007, p. 82). A terceira meta, no 22, que prevê a ampliação do Programa de garantia de renda mínima associada às ações socioeducativas, foi vetada pelo presidente na época, Fernando Henrique Cardoso.

A quarta meta, de $n^{\circ} 23$, que propõe a realização de estudos sobre o custo da educação infantil, com o intuito de melhorar a qualidade do atendimento desse nível de ensino, é analisada por Brandão (2007), o qual chama a atenção para o fato de que, para se atingir essa meta, necessário se faz, primeiramente, definir quais são os parâmetros de qualidade e enfatiza que é primordial que se atinja primeiro, “[...] uma série de disposições postas no conjunto das metas e objetivos estabelecidos por esse PNE para a educação infantil" (BRANDÃO, 2007, p. 84). No que se refere à questão da oferta e atendimento desse nível de ensino, assevera o autor que dificilmente serão alcançadas até a vigência desse documento, mesmo considerando a colaboração das diversas esferas do Poder Público para o atendimento das mesmas.

Em consonância com a legislação vigente e o processo histórico que acompanhou a trajetória das instituições de atendimento à infância, seja a creche ou a pré-escola, o Ministério da Educação, tomando por base seus documentos de 1994 e 1995, já citados anteriormente, definiu o ano de 2006 como o ano da Política Nacional de Educação Infantil, com suas diretrizes, objetivos, metas e estratégias para esse nível de ensino. Recomendando que:

A prática pedagógica considera os saberes produzidos no cotidiano por todos os sujeitos envolvidos no processo: crianças, professores, pais, comunidade e outros profissionais; Estados e municípios elaborem ou adéqüem seus planos de educação em consonância com a Política Nacional de Educação Infantil; as instituições de educação infantil ofereçam, no mínimo, quatro horas diárias de atendimento educacional, ampliando progressivamente para tempo integral, considerando a demanda real e as características da comunidade atendida nos seus aspectos sócio-econômicos e culturais; as instituições de Educação Infantil assegurem e divulguem iniciativas inovadoras, que levam ao avanço na produção de conhecimentos teóricos na área da educação infantil, sobre infância e a prática pedagógica; a reflexão coletiva sobre a prática pedagógica, com base nos conhecimentos historicamente produzidos, tanto pelas ciências quanto pela arte e pelos movimentos sociais, norteie as propostas de formação; os profissionais da instituição, as famílias, a comunidade e as crianças participem da elaboração, implementação e avaliação das políticas públicas. (BRASIL, 2006, p. 26).

Sobre os profissionais que trabalham com essa faixa etária, é importante ressaltar que, em função das novas exigências previstas na Lei, faz-se necessário uma formação inicial sólida e constante atualização em serviço. Em se tratando da criança pequena, a 
realidade tem apontado que ambas as formações é uma das variáveis que maior impacto causa sobre a qualidade desse tipo de atendimento. Essa preocupação é destacada por Kishimoto (2002) ao tratar dos avanços e retrocessos na formação de profissionais de educação infantil, porque um dos problemas encontrados na configuração curricular dos cursos que formam professores no Brasil refere-se à falta de clareza sobre o perfil profissional daqueles que vão atuar junto à criança pequena. A crítica mais comum está na natureza disciplinar do currículo, por serem os conteúdos organizados em campos disciplinares, dificultando qualquer possibilidade de reforma. Na realidade, a formação do professor que é desenvolvida no interior das universidades se organiza em campos disciplinares, criando-se tradições, feudos, em que "[...] priorizam-se determinados campos de conhecimento em detrimento de outros: em uns, saberes históricos e filosóficos, sociológicos e antropológicos ou organizacionais entre outros" (KISHIMOTO, 2002, p. 108).

$\mathrm{Na}$ perspectiva dessa autora, não é possível levar o futuro profissional a compreender que a criança pequena aprende de modo integrado, quando, no seu curso de formação, os conteúdos se apresentam de maneira fragmentada e em disciplinas estanques, que não dialogam entre si. Outro fato muito comum, encontrado na condução da prática pedagógica dos estágios, é que, geralmente, o aluno é colocado em contato com livros, proporcionando-lhe pouco contato com a realidade das escolas.

Para tanto, Barreto (1998) enfatiza que a formação de professores é reconhecidamente um dos fatores mais importantes para a promoção de padrões de qualidade na educação, qualquer que seja o grau ou modalidade. Destaca ainda que, embora a chamada formação continuada não deva se caracterizar como algo eventual, nem apenas um instrumento que se usa para suprir deficiências teóricas e práticas de uma formação acadêmica mal feita, é importante que esse profissional busque a capacitação em serviço e a atualização constante, aprofundando as experiências científicas e cotidianas que está vivendo e as vividas anteriormente. É importante que, ao longo da carreira do magistério, o mesmo possa frequentar não só os cursos de atualização, grupos de estudos ligados ao fazer pedagógico na sala de aula, mas, sobretudo, estar atento às questões políticas, sociais e econômicas, acompanhando as transformações da sociedade como um todo.

Os resultados da pesquisa apontam que, se muitos foram os avanços previstos na legislação, inversamente, muitos retrocessos acompanham a trajetória histórica dessas instituições, já que, do ponto de vista prático, o trabalho realizado no interior de muitas delas se restringe mais aos cuidados físicos relacionados à higienização e à alimentação do que propriamente um trabalho voltado aos aspectos educativos. A alta rotatividade no emprego, a falta de opção em relação a outros serviços, a baixa assiduidade e as características individuais de personalidade da cada profissional também interferem nesse processo.

Pesquisas recentes apontam que o cansaço físico das professoras é muito acentuado, porque o trabalho com as crianças menores exige muita habilidade física e preparo emocional. Sobre esta questão, Ongari (2003, p. 84) ressalta que o cansaço físico é percebido como importante se considerarmos que o trabalho com as crianças pequenas implica um modo de relação centrado na corporeidade, que pode se tornar pesado do ponto de vista físico. Além de raramente ficar parada, "[...] a educadora também carrega as crianças no colo, levanta-as, principalmente para a troca; e ainda, permanece sentada ao lado delas, freqüentemente no chão, o que exige muita energia sempre que for necessário se levantar". O cansaço psicológico também compromete esse trabalho, pois, a necessidade 
de estar sempre atenta e de satisfazer ao mesmo tempo às exigências de muitas crianças aparece como um interveniente no cotidiano das instituições.

A falta de uma metodologia adequada para o desenvolvimento de cada atividade, a excessiva escolarização ou a alfabetização precoce e a inexistência de um currículo que integre os cuidados à educação da criança, a pouca autonomia sobre a própria ação e a baixa remuneração também são questões que impedem um trabalho de mais qualidade. É importante destacar que a concretização de um bom trabalho junto às crianças se inicia pela maneira como os professores apropriam-se de modelos pedagógicos ao longo da carreira, haja vista que o contexto pedagógico requer estruturas curriculares abertas e flexíveis. Isso envolve nova concepção de currículo, entendido como trajetória de exploração partilhada de objetos de conhecimento de determinada cultura, por meio de atividades diversificadas, constantemente avaliadas (OLIVEIRA, 2002). Nessa perspectiva, o currículo não pode ser entendido como um plano individual, mas como um projeto coletivo que deve ser pensado e elaborado para o crescimento tanto do professor como das crianças. O planejamento do currículo inclui a organização de uma série de elementos que vai enriquecer o universo da escola infantil. Questões como a rotina, o tempo, o espaço, os materiais disponíveis, os brinquedos devem permear todo o desenvolvimento das atividades junto às crianças.

\footnotetext{
Planejar o currículo implica ouvir os profissionais em suas concepções e decisões, problematizar a visão deles sobre creches e pré-escolas, evitando perspectivas fragmentadas e contraditórias, que refletem a influência das várias concepções educacionais que vivenciaram ou com que tiveram contato. (OLIVEIRA, 2002, p. 168).
}

Não é tarefa fácil discutir sobre questões que tratam do trabalho pedagógico em instituições de educação infantil, uma vez que o cotidiano aponta para as muitas dificuldades do professor na organização desse trabalho, especialmente no que tange à rotina das crianças. Em geral, a própria literatura, quando aborda esta questão, centra-se mais no recorte de um ou outro aspecto que envolve o cotidiano da instituição, mas não fornece aos professores uma visão mais globalizante dos elementos que constituem o seu trabalho diário. No entanto, apesar de toda a problemática que ainda permeia uma grande maioria de instituições de atendimento à criança e apesar de terem tido no seu início uma função mais voltada para as questões assistenciais, apresentando, ainda hoje, muitos desses problemas, avançaram ao longo das décadas, apresentando diferentes funções no seu interior, até se consolidar como um espaço de educação para a criança pequena.

\section{Considerações Finais}

Este estudo nos permitiu trazer elementos para pensar a prática pedagógica desenvolvida no interior das escolas infantis e, sobretudo, chamar a atenção para a complexidade das relações que ocorrem no interior dessas instituições. Sua consolidação só aconteceu nas últimas décadas, em função dos movimentos sociais de luta e reivindicação pelos direitos humanos, dentre eles, o direito de todas as pessoas a uma educação de qualidade desde a mais tenra idade. As duas últimas décadas significaram um tempo de conquistas sobre os direitos da criança brasileira, a opção da família em dividir a educação com os filhos e o dever do Estado na garantia de todos esses direitos (Oliveira, 2002). Para além das questões que envolvem todos os percalços que comprometem uma 
educação mais qualitativa para essa faixa etária, consideramos que muitos são os desafios para o novo milênio. Elencamos aqueles que nos parecem mais relevantes no que tange à busca pela qualidade no interior das escolas infantis e divididos em grandes eixos, que são:

- Recursos financeiros aplicados, exclusivamente, nesse nível de ensino;

- Universalização do atendimento para todas as crianças de zero a cinco anos de idade;

- Formação inicial e continuada do professor que priorize a integração entre os cuidados e a educação da criança pequena;

- Projeto pedagógico adequado para essa faixa etária, que possibilite o enriquecimento das experiências infantis;

- trabalho coletivo entre a direção, coordenação, professor, demais funcionários da instituição e família das crianças

- ludicidade como elemento fundamental na organização do trabalho pedagógico;

- participação das famílias nas escolas infantis;

- espaço físico contendo mobiliário e material pedagógico adequado à idade das crianças;

- segurança física e psicológica que garanta o acolhimento a todas as crianças, inclusive às crianças especiais;

- articulação entre esse nível de ensino e os anos iniciais do ensino fundamental.

Ao pensar nos desafios propostos e nos muitos outros que podem contribuir para uma educação que respeite, efetivamente, o desenvolvimento e aprendizado da criança pequena, parafraseamos o pensamento de Bujes (2001) ao reconhecer que esse espaço deve ser muito mais qualificado e que, ao incluir o acolhimento e a segurança, também precisa ser um ambiente que desperte a emoção e desenvolva a sensibilidade, contemplando, assim, a curiosidade e a investigação dos pequenos infantes. Para tanto, nos baseamos nos dez aspectos-chave para uma educação infantil de qualidade, propostos por Zabala (1998, p. 50), de que, segundo ele "[...] a ordem não é importante, uma vez que a relevância de cada um dos aspectos mencionados deriva do seu conteúdo, não da sua posição na lista" e que se constituem: 1) organização dos espaços; 2) equilíbrio entre a iniciativa infantil e no trabalho dirigido no momento de planejar e desenvolver as atividades; 3) atenção privilegiada aos aspectos emocionais; 4) utilização de uma linguagem enriquecida; 5) diferenciação de atividades para abordar todas as dimensões do desenvolvimento de todas as capacidades; 6) rotinas estáveis; 7) materiais diversificados e polivalentes; 8) atenção individualizada a cada criança; 9) sistemas de avaliação, anotações que permitam o acompanhamento global do grupo e de cada uma das crianças; 10) trabalho com os pais e mães.

É conveniente ressaltar que a qualidade tem muitas leituras e pode ser analisada sob diferentes perspectivas. O importante é que a educação de qualidade da criança pequena possa ser reconhecida não só no plano legislativo e nos documentos oficiais, mas pela sociedade como um todo. Afinal essa modalidade educacional é de responsabilidade pública e, como tal, deve prioritariamente ser assumida por todos; esse é o nosso maior desafio. 


\section{Referências}

BARRETO, Ângela M. R. Situação atual da educação infantil no Brasil. In: BRASIL. Ministério da Educação e do Desporto. Subsídios para o credenciamento e funcionamento de instituições de educação infantil. v. 2. Coordenação Geral de educação infantil. Brasília: MEC/SEF/COEDI, 1998.

Ângela M. R. A educação infantil no contexto das políticas públicas. Revista Brasileira de Educação - Associação Nacional de Pós-Graduação e Pesquisa em Educação, Rio de Janeiro, Campinas, SP: Autores Associados, n. 24, p. 53-65, set./out./nov./dez. 2003.

BITTAR, M; SILVA, J.; MOTA, M. A .C. Formulação e implementação da política de educação infantil no Brasil. In: Educação infantil, política, formação e prática docente. Campo Grande, MS: UCDB, 2003.

BRANDÃO. Carlos da Fonseca. A educação infantil no Plano Nacional de Educação: a questão da oferta e do atendimento. In: PASCHOAL, Jaqueline. D. (Org.). Trabalho pedagógico na educação infantil. Londrina, PR: Humanidades, 2007. p.77-86.

BRASIL. Constituição da República Federativa do Brasil. Brasília, DF: Senado Federal, 1988, 305 p.

Estatuto da Criança e do Adolescente. Lei no 8.069, de 13 de junho de 1990.

Plano Nacional de Educação. Lei no 10.172/2001, de 09 de janeiro de 2001.

Ministério da Educação e do Desporto. Secretaria de Educação Fundamental. Política nacional de educação infantil. Brasília, DF: MEC/SEF/COEDI, 1994a.

Ministério da Educação e do Desporto. Secretaria de Educação Fundamental. Por uma política de formação do profissional de educação infantil. Brasília, DF: MEC/SEF/COEDI, 1994b.

Ministério da Educação e do Desporto. Critérios para um atendimento em creches que respeite os direitos fundamentais das crianças. Brasília, DF: MEC/SEF/COEDI, 1995.

Ministério da Educação e Cultura. Lei de Diretrizes e Bases da Educação Nacional. Lei $\mathrm{n}^{\circ}$ 9394, de 20 de dezembro de 1996. Dispõe sobre as Diretrizes e Bases da Educação Nacional. Brasília, DF: MEC, 1996.

Ministério da Educação e do Desporto. Secretaria de Educação Fundamental. Referencial curricular nacional para a educação infantil. Brasília, DF: MEC/SEF, 1998a.

Ministério da Educação e do Desporto. Secretaria de Educação Fundamental. Subsídios para o credenciamento e funcionamento de instituições de educação infantil. Coordenação Geral de Educação Infantil, v. 1 e 2. Brasília, DF: $\mathrm{MEC} / \mathrm{SEF} / \mathrm{DPE} / \mathrm{COEDI}, 1998 \mathrm{~b}$. 
Ministério da Educação e do Desporto. Secretaria de Educação Básica. Política nacional de educação infantil. Brasília, DF: MEC/SEB, 2006.

BUJES, Maria Isabel E. Escola infantil: pra que te quero?. In: CRAIDY, Carmem; KAERCHER, Gládis E.(Org). Educação Infantil: pra que te quero? Porto Alegre: Artmed Editora, 2001. p.13-23.

DIDONET, Vital. Creche: a que veio, para onde vai. In: Educação Infantil: a creche, um bom começo. Em Aberto/Instituto Nacional de Estudos e Pesquisas Educacionais. v 18, n. 73. Brasília, 2001. p.11-28.

FERREIRA, Maria Clotilde Rossetti (Org.). Os fazeres na educação infantil. São Paulo: Cortez, 2000.

HADDAD, Lenira. A creche em busca de identidade. São Paulo: Loyola, 1993.

KISHIMOTO, Tizuko Morchida. Avanços e retrocessos na formação dos profissionais de educação infantil. In: MACHADO, Maria Lúcia de A. (Org.) Encontros e desencontros em educação infantil. São Paulo: Cortez, 2002. p. 107-115.

KRAMER, Sonia. A política do pré-escolar no Brasil: a arte do disfarce. 5. ed. São Paulo: Cortez,1995.

KUHLMANN JR., Moisés. Infância e educação infantil: uma abordagem histórica. Porto Alegre: Mediação, 1998.

O jardim de infância e a educação das crianças pobres: final do século XIX, início do século XX. In: MONARCHA, Carlos, (Org.). Educação da infância brasileira: 18751983. Campinas, SP: Autores Associados, 2001. p. 3-30 (Coleção educação contemporânea).

LEITE FILHO, A. Proposições para uma educação infantil cidadã. In: GARCIA, R. L.; LEITE FILHO, A. (Orgs.). Em defesa da educação infantil. Rio de Janeiro: DP\&A, 2001. p. 29-58. (Coleção O sentido da escola; 18).

MARCÍLIO, Maria Luiza. A roda dos expostos e a criança abandonada na História do Brasil. In: FREITAS, Marcos Cezar (Org.). História social da infância no Brasil. São Paulo: Cortez, 1997. p. 51-76.

MARX, Karl. Divisão do trabalho e manufatura. In: O Capital. São Paulo: Difel, 1. 1, v. 1, 1982. p. 386-422.

O Capital. 1.1, v.1. São Paulo: Bertrand Brasil-Difel, 1986. p. 423-550.

OLIVEIRA, Zilma Moraes R. Creches: Crianças, faz de conta \& Cia. Petrópolis, RJ: Vozes, 1992. 
Zilma Moraes R. Educação infantil: fundamentos e métodos. São Paulo: Cortez, 2002. (Coleção Docência em Formação).

ONGARI, Bárbara; MOLINA, Paola. A educadora de creche: construindo suas identidades. Tradução: Fernanda L. Ortale e Ilse Paschoal Moreira. São Paulo: Cortez, 2003.

RIZZO, Gilda. Creche: organização, currículo, montagem e funcionamento. 3. ed. Rio de Janeiro: Bertrand Brasil, 2003.

ZABALZA, Miguel. A . Qualidade em educação infantil. Trad. Beatriz Affonso Neves. Porto Alegre: ArtMed, 1998.

\footnotetext{
${ }^{1}$ Mestre em Educação. Doutoranda no Curso de Pós-Graduação em Educação pela Universidade Estadual de Maringá/UEM. Docente no Departamento de Educação da Universidade Estadual de Londrina.

${ }^{2}$ Doutora em Educação. Docente do Departamento de Fundamentos da Educação e do Programa de PósGraduação em Educação da Universidade Estadual de Maringá/UEM.

${ }^{3}$ Utilizaremos a expressão "pré-escola" e não mais jardim de infância, por consequência da mudança da terminologia a partir da década de setenta do século XX.

${ }^{4}$ Considerando a Lei $n^{\circ} 11.274$, de 6 de fevereiro de 2006, que determinou que o Ensino Fundamental no Brasil passaria a ter duração de nove anos, iniciando-se aos seis anos de idade, a educação infantil, a partir dessa data, corresponde à faixa etária de zero a cinco anos de idade e não mais até aos seis anos.

${ }^{5} \mathrm{O}$ presente documento contém 267 capítulos, e dispõe sobre a proteção integral à criança e ao adolescente no Brasil.
}

Artigo recebido em:

Aprovado para publicação em: 